\title{
Evaluation of the antibacterial and antifungal potential of spider saxifrage plant (Saxifraga flagellaris Willd.)
}

Khushnood ur Rehman ${ }^{1}$, Sher Wali ${ }^{1 *}$, Naveed Akhtar ${ }^{1}$, Barkat Ullah ${ }^{1}$, Sumera Afzal $^{2}$, Imtiaz Ahmad ${ }^{3}$ and Muhammad Hamayun ${ }^{4}$

1. Department of Botany, Islamia College, Peshawar, Peshawar-Pakistan

2. Centre of Biotechnology, University of Peshawar, Peshawar-Pakistan

3. Department of Botany, Bacha Khan University, Charsadda-Pakistan

4. Department of Botany, Abdul Wali Khan University, Mardan-Pakistan

*Corresponding author's email: sherwali@icp.edu.pk

Citation

Khushnood ur Rehman, Sher Wali, Naveed Akhtar, Barkat Ullah, Sumera Afzal, Imtiaz Ahmad and Muhammad Hamayun. Evaluation of the antibacterial and antifungal potential of spider saxifrage plant (Saxifraga flagellaris Willd.). Pure and Applied Biology. Vol. 8, Issue 2, pp1163-1171. http://dx.doi.org/10.19045/bspab.2019.80058

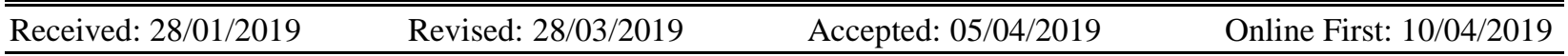

\section{Abstract}

The current research work was performed to find antifungal and antibacterial potential of spider saxifrage plant. The aim was to find a new source against the selected pathogenic bacterial and fungal strains. Saxifraga flagellaris extract was fractionated. Five fractions were prepared and tested for antimicrobial potential against the selected fungal and bacterial strains. The highest antifungal activity (35-65\%) was displayed by the crude methanolic extract against all the selected fungal stains and the lowest antifungal trend was exhibited by the aqueous fraction. However in antibacterial activity the $\mathrm{n}$-hexane fraction showed maximum antibacterial activity (46-48\%) against the selected pathogens and more or less same trend was followed by crude methanolic extract, while the least inhibition was shown by aqueous fraction. The other fractions though remained with moderate zone of inhibition but were significant.

Keywords: Antibacterial; Antifungal; Inhibition; Spider Saxifrage; Saxifraga flagellaris

\section{Introduction}

Plants' primary or secondary metabolites are natural products. Primary metabolites are necessary for the growth and development wile secondary metabolites govern the biochemical pathways [1]. Secondary metabolites are formed from the primary metabolites via biosynthetic pathways and may or may not be linked to the growth of the plant but have significant ecological functions. The commercial applications of these extracts include different flavorings, fragrances and drugs synthesis etc. [2]. There is enormous diversity in the nature of the plants derived secondary metabolites. Plants have medicinal properties due to the presence of certain secondary metabolites [3]. According to [4] these compounds are specific at different taxonomic ranks like subspecies, species, genera and families. About $50 \%$ of the medicines introduced into the market in the last two decades have been obtained from medicinal plants [5]. Modern screening methods have given medicinal plants amazing importance because of the enhanced biological impact, structural 
confirmation and isolation of active metabolites. Currently three generations of medicinal plants are identified [6]. Based on the enormous availability of the biochemical variety; medicinal plants provide a limitless resource of the new drugs discovery $[7,8]$. About $25 \%$ of the medications and $66 \%$ of the anti-inflammatory and anticancer drugs in market and laboratory trials are of the medicinal plants origin [9]. Based on the fact that microbes become resistant over time, the antibiotics; which play a fundamental role in the treatment of infectious diseases; become less effective which results in the increasing failures of the therapies. These diseases caused about $50 \%$ of the deaths globally and became the $3^{\text {rd }}$ major reason of deaths [10]. For the treatment of bacterial diseases hundreds of plants derived precuts are used [11]. The use of plant natural products is ever increasing by the local communities. Berberine and quinines are examples of these products [12]. Similarly liposomes can be used to detoxify the toxins produced by Streptococcus pneumonia and $S$. aureus. Azorella cryptantha's product Chrysolthol exhibit very strong activities against $S$. enteritidis and E. coli [13]. Similarly the leaves extract of Catharanthus roseus were active against the species of Streptococcus, Pseudomonas and E. coli [14]. Fungi are one of the infectious agents causing dreadful diseases and posing as a cause among the others in global health problems [15]. Fungi have dual threatening effects as these not only cause severe ailments in economic crops but also allergies and toxicities [16, 17]. Fungicides of biological origin have commonly been used to cure fungal ailments. Due to the continuous arise of the resistant varieties there is an ever growing demand for harmless alternative and useful compounds [18]. The species, e.g. Aloe vera containing C-glucoside Barbaloin, with effective antifungal properties can yield biologically active products $[19,20]$. Assessment of the antifungal activities of local Brazilian medicinal plants showed that the most vigorous were the methanolic extracts of Vernonia polyanthes [21]. Similarly the growth of Mycosphaerella eumusae can be inhibited by different extracts obtained from Allium sativum [22]. In this regard the current research work was designed with the aim to evaluate the antibacterial and antifungal activities of Saxifraga flagellaris WILLD.

\section{Materials and methods}

Antibacterial activity

Media preparation and agar well diffusion method

Following [23] agar well diffusion Method was used for antibacterial activity. 1 liter distilled of water was used to liquefy $25 \mathrm{~g}$ of Luria Broth, Miller powder at $\mathrm{pH}$ adjusted at 7.0. $100 \mathrm{ml}$ of this media were autoclaved in $250 \mathrm{ml}$ flask. The selected bacterial strains were introduced into the flasks and kept overnight at $150 \mathrm{RPM}$ at $37^{\circ} \mathrm{C}$. The agar was allowed to solidify in the petri-dishes and after that 5 holes were tunneled through a sterilized borer. The tunnels were then introduced with the inoculums. The bacterial and fungal strains were selected based on their frequent occurrence in the local hospitals and their resistance to common drugs.

\section{Tested bacterial strains}

The selected fungal strains included three gram positive strains i.e. Staphylococcus aureus, Streptococcus mutans and Methicillin-resistant Staphylococcus aureus (MRSA) and a single gram negative strain i.e. Serratia marcescens.

\section{Extract preparation and measurement of} zones of inhibition

The crude extract of Saxifraga flagellaris were dissolved in $20 \mathrm{mg} / \mathrm{ml}$ of Dimethyl sulfoxide (DMSO). Standard antibiotic; Cefotaxime $(2 \mathrm{mg} / \mathrm{ml})$ was used as positive control while pure DMSO as negative control. $75 \mu \mathrm{l}$ of the plant fraction was introduced into the wells in petri-dishes. The 
samples were incubated for 24 hours at $37^{\circ} \mathrm{C}$. After incubation diameter of the transparent zone, around each well was measured. The experiment was repeated thrice and standard deviation was calculated from the data obtained.

\section{Antifungal activity \\ Media preparation and agar well diffusion method}

Potato dextrose agar (39g) was taken in liter distilled water (1 liter). The mixture was sterilized at 15PSI for 15 minutes in the autoclave. It was cooled at room temperature and poured into the petri-dishes to solidify. The method of [24] i.e. agar well diffusion method was followed. $100 \mu 1$ of different strains of the selected fungal strains were placed on the surface of agar plate through a micropipette. The culture was spread by a sterilized inoculation loop. Holes were made in the culture (Plate 1) via a sterile cork borer. Crude extract $(75 \mathrm{ml})$ of the Saxifraga flagellaris were added to the petri-dishes and incubated at $37^{\circ} \mathrm{C}$ for 24 hours. Results were calculated by measuring the clear areas around each hole which indicated the extent of antifungal activity of each extract against the tested fungal strain. Each test was repeated thrice and the data was analyzed statistically.

\section{Tested fungal strains}

The selected fungal strains included Alternaria alternate, Aspergillus flavus, Polysphondylium pallidum and Fusarium oxysporum.

\section{Results and discussion}

The current research work was carried out to evaluate the anti-fungal and anti-bacterial potential of the spider saxifrage plant (Saxifraga flagellaris WILLD.) plant. The results revealed that this plant is a very effective source for the inhibition of the growth of the tested species of both fungi and bacteria. The plant can be investigated for active metabolites to evolve the anti-bacterial and anti-fungal drugs through biochemical and biophysical essays.

\section{Antibacterial activities of Saxifraga flagellaris}

In the current research work five fractions of Saxifraga flagellaris extracts were used to know their potential use against the selected bacterial strains that are Staphylococcus aureus, Streptococcus mutans and Methicillin-resistant Staphylococcus aureus (MRSA) and Serratia marcescens. These species were selected for the current experiments on the basis of their frequent pathological reports from hospitals of Khyber Pakhtunkhwa. Results of the anti-fungal activity as shown in (Table 1) showed that all the fractions were active against the tested bacterial strains. The growth of Staphylococcus aureus, Streptococcus mutans, Serratia marcescens and Methicillin-resistant Staphylococcus aureus (MRSA) was inhibited by the crude methanolic extract with $10.0 \mathrm{~mm}, 12.0 \mathrm{~mm}$, $09.0 \mathrm{~mm}$ and $11.0 \mathrm{~mm}$ zones of inhibition respectively. The $n$. hexane extracted fractions inhibited the growth of Staphylococcus aureus, Streptococcus mutans, Serratia marcescens and Methicillin-resistant Staphylococcus aureus (MRSA) with $12.0 \mathrm{~mm}, 13.0 \mathrm{~mm}, 14.0 \mathrm{~mm}$ and $10.0 \mathrm{~mm}$ zones of inhibition respectively. The chloroform fractions were produced $11.0 \mathrm{~mm}, 14.0 \mathrm{~mm}, 07.0 \mathrm{~mm}$ and $14.0 \mathrm{~mm}$ zones of inhibition against Staphylococcus aureus, Streptococcus mutans, Serratia marcescens and Methicillin-resistant Staphylococcus aureus (MRSA) respectively. The ethyl acetate fraction was most active against Streptococcus mutans (ZOI $=10.0 \mathrm{~mm})$ followed by Methicillinresistant Staphylococcus aureus (ZOI=09.0mm), Staphylococcus aureus $(\mathrm{ZOI}=08.0 \mathrm{~mm})$ and Serratia marcescens $(\mathrm{ZOI}=08.0 \mathrm{~mm})$. The aqueous extracted fraction inhibited the growth of tested bactrail strains in the order of Methicillin- 
resistant Staphylococcus aureus (ZOI $=08.0 \mathrm{~mm}), \quad$ Staphylococcus aureus (ZOI $=05.0 \mathrm{~mm}), \quad$ Serratia marcescens (ZOI $=05.0 \mathrm{~mm})$ and Streptococcus mutans (ZOI $=04.0 \mathrm{~mm})$ respectively. Globally several hundred genera of medicinal plants are used as the main sources of anti-bacterial drugs $[25,26]$. According to $[27,28]$ in the previous century most of the faculties in the medicine sector switched their concern from natural to synthetic drugs. But for the last few decades this trend is shifting in the reverse direction [29]. In a survey $25 \%$ of the drug prescriptions in 35 countries are plants derived in non-modified or little modified $[30,31]$.

\section{Antifungal activities of Saxifraga flagellaris}

Results of the anti-fungal activity as shown in (Table 2) showed that the n-hexane extracted sample inhibited the growth of Fusarium oxysporum completely. Chloroform and Ethyl acetate inhibited the growth of Polysphondylium pallidum. While the aqueous extract showed significant activity against Aspergillus flavus and Alternaria alternate. Crude methanolic extract showed good results against Polysphondylium pallidum. Trend in results revealed that Fusarium oxysporum is comparatively more sensitive to the n-hexane extracts, Polysphondylium pallidum to chloroform and Ethyl acetate extracts while Aspergillus flavus and Alternaria alternate to the aqueous extracts of plants. The usage of medicinal plants as anti-fungals is quite old practice performed by human beings. These result in the production of important compounds that are used to develop drugs against fungal pathogens. One of the positive aspects of these drugs is this that these drugs have very little adverse/side effects on the human health [32]. The demand for the development anti-fungal drugs has enormously increased as it is established that among others fungal pathogens are causing serious losses in the quantity, quality, shelf life and mortality of the crop plants [33]. In regard to humans, fungi as the cause of diseases offer a new aspect of human pathology [34]. In this regard medicinal plants are proved to be the sources for the discovery of new drugs [35]. In the developing countries, which face the problems of the quantity and quality of modern drugs, medicinal plants derived compounds have recently gained much importance and their old traditional uses are valued much more nowadays [36-38]. The current study revealed that antifungal activity of the wild plants proved to be much more significant and can be a very suitable substitute of the modern medicines. Similar findings have been reported by [39] for the fungus Alternaria alternate. Similarly [40] revealed that the crude methanolic extract of the medicinal plants showed maximum antifungal properties which is in agreement with our work. Similar results with other medicinal plants were reported by [41]. 

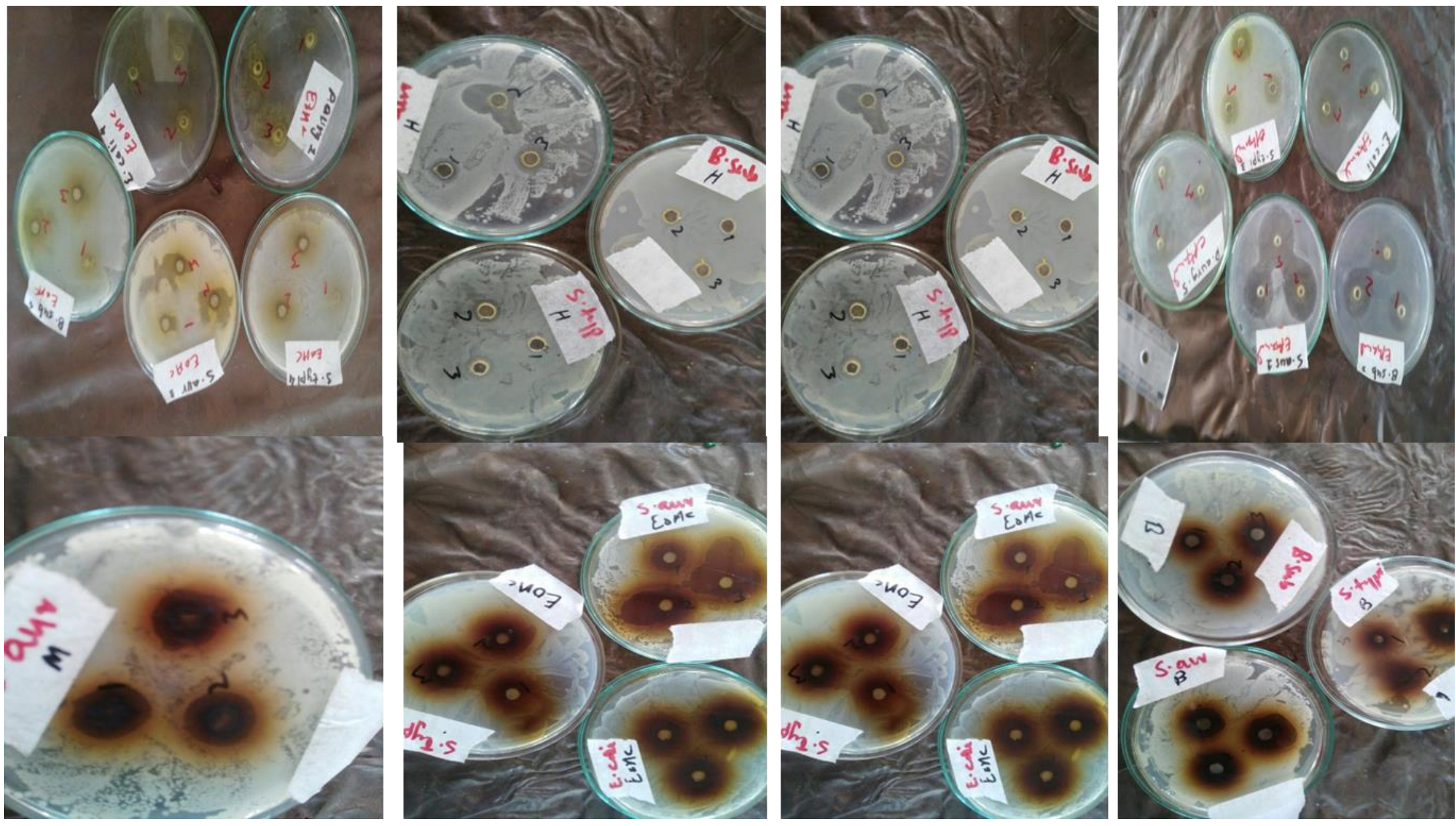

Plate 1. Petri Plates showing the antibacterial and antifungal activities of Saxifraga flagellaris 
Rehman et al.

Table 1. Antibacterial activity of the crude extracts of Saxifraga flagellaris Willd

\begin{tabular}{|c|c|c|c|c|c|c|c|c|c|c|c|}
\hline \multirow{2}{*}{ Bacterial Species } & \multirow{2}{*}{ Standard } & \multicolumn{2}{|c|}{ Cr. Met. Ext } & \multicolumn{2}{|c|}{$n$-hexane } & \multicolumn{2}{|c|}{$\mathrm{CHCl}_{3}$} & \multicolumn{2}{|c|}{ EtOAc } & \multicolumn{2}{|c|}{ Aqueous } \\
\hline & & ZOI & $\%$ & ZOI & $\%$ & ZOI & $\%$ & ZOI & $\%$ & ZOI & $\%$ \\
\hline MRSA & $25.0 \pm 0.67$ & $11.0 \pm 0.93$ & 44.00 & $12.0 \pm 0.90$ & 48.00 & $10.0 \pm 0.57$ & 40.00 & $09.0 \pm 0.87$ & 36.00 & $08.0 \pm 0.23$ & 32.00 \\
\hline S. marcescens & $21.0 \pm 0.87$ & $09.0 \pm 0.56$ & 42.86 & $10.0 \pm 0.88$ & 47.62 & $07.0 \pm 0.45$ & 33.33 & $08.0 \pm 0.44$ & 38.1 & $05.0 \pm 0.22$ & 23.81 \\
\hline S. mutans & $28.0 \pm 0.60$ & $12.0 \pm 0.67$ & 42.86 & $13.0 \pm 0.66$ & 46.43 & $14.0 \pm 0.56$ & 50.00 & $10.0 \pm 0.34$ & 35.71 & $04.0 \pm 0.34$ & 14.29 \\
\hline S. aureus & $26.0 \pm 0.56$ & $10.0 \pm 0.87$ & 38.46 & $12.0 \pm 0.93$ & 46.15 & $11.0 \pm 0.21$ & 42.31 & $08.0 \pm 0.33$ & 30.77 & $05.0 \pm 0.50$ & 19.23 \\
\hline
\end{tabular}

Table 2. Antifungal activity of the crude extracts of Saxifraga flagellaris Willd

\begin{tabular}{|c|c|c|c|c|c|c|c|c|c|c|c|}
\hline \multirow{2}{*}{ Fungal Species } & \multirow{2}{*}{ Standard } & \multicolumn{2}{|c|}{ Cr. Met. Ext } & \multicolumn{2}{|c|}{$n$-hexane } & \multicolumn{2}{|c|}{$\mathrm{CHCl}_{3}$} & \multicolumn{2}{|c|}{ EtOAc } & \multicolumn{2}{|c|}{ Aqueous } \\
\hline & & ZOI & $\%$ & ZOI & $\%$ & $\mathrm{ZOI}$ & $\%$ & ZOI & $\%$ & $\mathrm{ZOI}$ & $\%$ \\
\hline A.flavus & $100.0 \pm 0.00$ & $45.0 \pm 0.55$ & 45 & $45.0 \pm 0.78$ & 45 & $30.0 \pm 0.67$ & 30 & $40.0 \pm 0.34$ & 40 & $0.0 \pm 0.00$ & 0 \\
\hline A. alternate & $100.0 \pm 0.00$ & $65.0 \pm 0.54$ & 65 & $30.0 \pm 0.88$ & 30 & $45.0 \pm 0.56$ & 45 & $40.0 \pm 0.10$ & 40 & $0.0 \pm 0.00$ & 0 \\
\hline F. oxysporum & $100.0 \pm 0.00$ & $57.0 \pm 0.23$ & 57 & $00.0 \pm 0.00$ & 0 & $32.0 \pm 0.77$ & 32 & $30.0 \pm 0.22$ & 30 & $23.0 \pm 0.34$ & 23 \\
\hline P. pallidum & $100.0 \pm 0.00$ & $35.0 \pm 0.44$ & 35 & $29.0 \pm 0.67$ & 29 & $00.0 \pm 0.00$ & 0 & $00.0 \pm 0.00$ & 0 & $30.0 \pm 0.21$ & 30 \\
\hline
\end{tabular}




\section{Conclusion}

It is evident from the results of anti-bacterial and anti-fungal activities that the selected plant i.e. Saxifraga flagellaris possessed very significant properties. The crude methanolic and ethanolic extracts were comparatively more active which clarified that polar solvents dissolved more properly in the polar solvents.

\section{Authors' contributions}

Conceived and designed the experiments: $\mathrm{M}$ Hamayun, KU Rehman \& S Wali, Performed the experiments: KU Rehman, S Wali \& I Ahmad, Analyzed the data: N Akhtar, B Ullah \& S Afzal, Contributed materials/ analysis/ tools: M Hamayun, N Akhtar, B Ullah \& S Afzal, Wrote the paper: KU Rehman \& S Wali.

\section{References}

1. Martin GJ (1995). Ethnobotany: a methods manual, Earthscan.

2. Balandrin MF, Klocke JA, Wurtele ES \& Bollinger WH (1985). Natural plant chemicals: sources of industrial and medicinal materials. Sci 228: 1154-1160.

3. Mdlolo CM (2009). Phytochemical analysis and selected biological activity of Phyllanthus parvulus Sond. var garipensis. Thesis (M.Sc.), Faculty of Science and Agriculture, University of Zululand, Kwa Dlangezwa,

4. Adelaja AA, Ayoola M, Otulana J, Akinola O, Olayiwola A \& Ejiwunmi A (2008). Evaluation of the histogastroprotective and antimicrobial activities of Heliotropium indicum Linn (Boraginaceae). The Malaysian J of Med Sci 15: 22.

5. Huang W, Cai, Y, Hyde K, Corke H \& SUN M (2008). Biodiversity of endophytic fungi associated with 29 traditional Chinese medicinal plants. Fungal Div 33: 61-75

6. Sarkar R, Meinberg, EG, Stanley JC, Gordon D \& Webb RC (1996) Nitric oxide reversibly inhibits the migration of cultured vascular smooth muscle cells. Circulation Res 78: 225-230.

7. Sasidharan S, Chen Y, Saravanan D, Sundram K \& Latha LY (2011). Extraction, isolation and characterization of bioactive compounds from plants' extracts. African J of Tradit Compl and Alternative Med 8.

8. Cowan MM (1999) Plant products as antimicrobial agents. Clinical Microbiol Rev 12: 564-582.

9. Rates SMK (2001). Plants as source of drugs. Toxicon, 39: 603-613.

10. Pinner RW, Teutsch SM, Simonsen L, Klug LA, Graber JM, Clarke MJ \& Berkelman RL (1996). Trends in infectious diseases mortality in the United States. Jama 275: 189-193.

11. Martin GS, Mannino DM, Eaton S \& Moss M (2003). The epidemiology of sepsis in the United States from 1979 through 2000. New England J of Med 348: 1546-1554.

12. Mustapha F, Jai J, Hamidon F, Sharif ZM \& Yusof NM (2017). Antimicrobial agents from Malaysian plants and their potential use in food packaging material. Chem Engi Res Bulletin 19: 57-66.

13. Lima IO, Pereira FO, Oliveira WA, Lima EO, Menezes EA, Cunha FA, Diniz MFFM. (2013). Antifungal activity and mode of action of carvacrol against Candida albicans strains. J Essent Oil Res 25: $138-142$.

14. Pina-Pérez M \& Pérez MF (2017). Antimicrobial potential of legume extracts against foodborne pathogens: A review. Trends in Food Sci \& Technol 72: 114-124

15. Wekesa VN (2017). Characterization and Antimicrobial Activity of Fungal Endophytes from Selected Kenyan Medicinal Plants. Egerton University.

16. Ahmad N, Amir M, Ayaz S, Jan A, Ashraf J \& Zuhra FT (2017). Antimicrobial profile of the selected 
medicinal plants. Inter J of Chem and Life Sci 1: 1039-1041.

17. Rouhi-Boroujeni H, Heidarian, E, RouhiBoroujeni H, Deris F \& Rafieian-Kopaei M (2017). Medicinal plants with multiple effects on cardiovascular diseases: A systematic review. Current Pharm Des 23: 999-1015.

18. Dahar GY \& Ismail M (2017). In-Vitro Evaluation of Plant Extracts against Sudden Death Disease Trees. Sci 5: 3137.

19. Grayer RJ \& Harborne JB (1994). A survey of antifungal compounds from higher plants, 1982-1993. Phytochem 37: 19-42.

20. Braga FG, Bouzada MLM, Fabri RL, Matos MDO, Moreira FO, Scio E \& Coimbra ES (2007). Antileishmanial and antifungal activity of plants used in traditional medicine in Brazil. $J$ of Ethnopharmacol 111: 396-402.

21. Portillo A, Vila R, Freixa B, Adzet T \& Cañigueral S (2001). Antifungal activity of Paraguayan plants used in traditional medicine. J of Ethnopharmacol 76: 9398.

22. Boller T (1988). Ethylene and the regulation of antifungal hydrolases in plants. Oxford Surveys of Plant Molecular and Cell Biology (United Kingdom).

23. Perez G, Avila A \& Martinez C (1990). Antimicrobial activity of some American algae. J of Ethnopharmacol 29: 111-116.

24. Samie A, Tambani T, Harshfield E, Green E, Ramalivhana $\mathrm{J} \&$ Bessong $\mathrm{P}$ (2010). Antifungal activities of selected Venda medicinal plants against Candida albicans, Candida krusei and Cryptococcus neoformans isolated from South African AIDS patients. African J of Biotechnol 9.

25. Perry LM \& Metzger J (1980). Medicinal plants of east and southeast Asia: attributed properties and uses, MIT press.
26. Sofowora A (1982). Medicinal plants and traditional medicine in Africa, John Wiley and sons LTD.

27. Hebbar S, Harsha V, Shripathi V \& Hegde $G$ (2004). Ethnomedicine of Dharwad district in Karnataka, Indiaplants used in oral health care. $J$ of Ethnopharmacol 94: 261-266.

28. Bauer A \& Brönstrup M (2014). Industrial natural product chemistry for drug discovery and development. Nat Product Rep 31: 35-60.

29. Hoareau L \& Dasilva EJ (1999). Medicinal plants: a re-emerging health aid. Electronic J of Biotechnol 2: 3-4.

30. Health GIFTSO (1997). Medicinal plants for forest conservation and health care, Food \& Agriculture Org.

31. Bahadur B, Janardhan RK \& Rao M (2007). Medicinal plants: an overview. Advances in Medicinal Plants. University Press (India) Pvt. Ltd. Hyderabad, 14-36.

32. Rios J \& Recio M (2005). Medicinal plants and antimicrobial activity. $J$ of Ethnopharmacol 100: 80-84.

33. Redo M, Rios J \& Villar A (1989). A review of some antimicrobial compounds isolated from medicinal plants reported in the literature 1978-1988. Phytotherapy Research, 3, 117-125.

34. Bansod S \& Rai M (2008). Antifungal activity of essential oils from Indian medicinal plants against human pathogenic Aspergillus fumigatus and A. niger. World J of Med Sci 3: 81-88.

35. Silva N \& Fernandes-Júnior A (2010). Biological properties of medicinal plants: a review of their antimicrobial activity. $J$ of Ven Ani and Tox Includ Trop Dis 16: 402-413.

36. Shinwari ZK, Ahmad N, Hussain J \& Rehman NU (2013). Antimicrobial evaluation and proximate profile of Nepeta leavigata, Nepeta kurramensis and Rhynchosia reniformis. Pak J Bot 45: 253-259. 
37. Ullah M, Khan MU, Mahmood A, Malik RN, Hussain M, Wazir SM, Daud M \& Shinwari ZK (2013). An ethnobotanical survey of indigenous medicinal plants in Wana district south Waziristan agency, Pakistan. J of Ethnopharmacol 150: 918924.

38. Balouiri M, Sadiki M \& Ibnsouda SK (2016). Methods for in vitro evaluating antimicrobial activity: A review. $J$ of Pharm Anal 6: 71-79.

39. Hadizadeh I, Peivastegan B \& Hamzehzarghani H (2009). Antifungal activity of essential oils from some medicinal plants of Iran against Alternaria alternate. American J of Appl Sci 6: 857-861.

40. Ali S, Ali K, Hussain Z, Khan MS, Khan WM, Wali S and Shuaib M (2017) Phytochemical screening and antimicrobial activity of selected medicinal plant species. Pure Appl Bio 6: 418-425.

41. Duraipandiyan V, Ayyanar M \& Ignacimuthu S (2006). Antimicrobial activity of some ethnomedicinal plants used by Paliyar tribe from Tamil Nadu, India. BMC Compl and Alter Med 6: 35. 